\title{
Hacia una gestión sostenible de las actividades turísticas en los espacios rurales y naturales
}

\author{
Violante Martínez \\ UNED \\ vmartin@poli.uned.es \\ Rocío Blanco \\ Universidad de Extremadura \\ rblanco@unex.es
}

Resumen: El turismo de naturaleza está estrechamente relacionado con el desarrollo y el turismo sostenibles, y su campo de actuación se circunscribe a los hábitats naturales $y$ su biodiversidad. En este ámbito destacan elementos como los parques naturales, las reservas protegidas, el ecoturismo, el hábitat rural, el agroturismo y el compromiso de la población autóctona del área concreta de implantación turística. El eje que va a dominar en las actividades y recreaciones que se desarrollen en la naturaleza es la sostenibilidad, de modo que la atención al turismo sostenible es imprescindible para contribuir a la conservación del medio ambiente, y requiere conocer los motivos para desarrollarlo en todo el territorio de espacios rurales y naturales.

Se tratan, por tanto, las consecuencias y repercusiones de la actividad ocioturística en el medio ambiente, por lo que se abordarán tanto los impactos positivos del ocio y el turismo en la naturaleza como los negativos, además de algunas recomendaciones para la sostenibilidad de las actividades ocioturísticas. Finalmente, el ocio y el turismo en la naturaleza dan cuenta del ámbito general del territorio en el que se va a implementar el turismo de naturaleza, que supone la tipología central de interacción de turismos rurales $y$ naturales, $y$ que está estrechamente vinculado en un primer orden con el turismo rural y el turismo activo $y$, en un segundo orden, con el agroturismo, el ecoturismo, el turismo sostenible, el turismo responsable, el turismo de aventura y el turismo deportivo.

Palabras clave: desarrollo turístico, sostenibilidad, turismo de naturaleza, turismo rural, turismo activo. 
Abstract: Natural tourism is closely related to developmental and sustainable tourism. Its field of action is circumscribed to natural habitats and their biodiversity. Of particular importance are natural parks, protected reserves, ecotourism, the rural habitat, agrotourism, and the local population's commitment of a particular area of implantation. The main point around which all these activities revolve is sustainability, so special attention is paid to sustainable tourism because of the contribution it makes to the environment. This requires certain knowledge of the reasons to develop it in all the rural and natural spaces.

Here we discuss the effects of leisure-related activities on the environment, and the positive and negative impacts that leisure and tourism can have on nature. We also make some recommendations about the sustainability of leisure-related tourism activities. Finally, leisure and tourism in nature reflect the general sphere of the territory in which Nature Tourism is going to be implemented, which entails the central typology in the interaction between Rural Tourism and Active Tourism, and at a minor scale Agrotourism, Ecotourism, Sustainable Tourism, Responsible Tourism, Adventure Tourism, and Sport Tourism.

Key words: Tourism development, Sustainability, Nature tourism, Rural tourism, Active tourism. 


\section{Hacia una sostenibilidad del turismo de naturaleza: impactos positivos y negativos}

Es conveniente subrayar que la actividad turística en los espacios naturales ha adquirido gran importancia desde finales del siglo $\mathrm{xx}$ y es la tipología turística que se ha venido desarrollando con mayor intensidad en los últimos años. Este tipo de turismo se diferencia del turismo convencional por las motivaciones y conductas de los turistas y por la singularidad de los recursos utilizados, que tienen un alto valor ecológico o paisajístico, y en muchas ocasiones se lleva a cabo en espacios protegidos por la legislación ambiental. Como señala Martínez Quintana (2009), se trata de una modalidad que está estrechamente relacionada con el desarrollo y el turismo sostenibles y su campo de actuación se circunscribe a los hábitats naturales y a su biodiversidad. En este ámbito destacan elementos como los parques naturales, las reservas protegidas, el ecoturismo, el hábitat rural, el agroturismo y el compromiso de la población autóctona del área concreta de implantación turística.

En 1999, la Comisión de las Naciones Unidas sobre el Desarrollo Sostenible, reunida en Nueva York, aprobó la creación del Código Ético Mundial para el Turismo y pidió a la OMT que recabara nuevas aportaciones del sector privado, de las organizaciones no gubernamentales y de las organizaciones sindicales. Se recibieron observaciones escritas sobre el Código de más de 70 estados miembros de la OMT y otras entidades. El Código Ético Mundial para el Turismo es, por tanto, la culminación de un completo proceso de consulta. Está compuesto por diez artículos que fueron aprobados por unanimidad en la reunión de la Asamblea General de la OMT en Santiago de Chile, en octubre de 1999.

Dentro de su articulado (concretamente, en el artículo n. 3 , apartados 4 y 5 ), este código refleja de forma clara y concisa la importancia del turismo de naturaleza y su imbricación con el desarrollo sostenible, como factor que contribuye a este:

Artículo 3. El turismo, factor de desarrollo sostenible. 4) Se concebirá la infraestructura y se programarán las actividades turísticas de forma que se proteja el patrimonio natural que constituyen los ecosistemas y la diversidad biológica, y que se preserven las especies en peligro de la fauna y de la flora silvestre. Los agentes del desarrollo turístico, y en particular los profesionales del sector, deben admitir que se impongan limitaciones a sus actividades cuando estas se ejerzan en espacios particularmente vulnerables: regiones desérticas, polares o de alta montaña, litorales, selvas tropicales o zonas húmedas, que sean idóneos para la creación de parques naturales o reservas protegidas. 5) El turismo de naturaleza y el ecoturismo se reconocen como formas de turismo 
particularmente enriquecedoras y valorizadoras, siempre que respeten el patrimonio natural y la población local y se ajusten a la capacidad de ocupación de los lugares turísticos (Código Ético Mundial para el Turismo, Naciones Unidas y OMT, 2001).

A priori, la oferta en el turismo de naturaleza debe ser de bajo impacto ambiental. Se trata de un turismo que se presupone muy respetuoso con la naturaleza y con la población local. Precisamente cuando se toma conciencia de las amenazas y los riesgos que comportan las actividades turísticas para los ecosistemas - que se evidencian a través de impactos negativos a nivel ecológico, social y cultural - es cuando el turismo de naturaleza empieza a adquirir una relevancia significativa. Siguiendo a Martínez Quintana (2009: 278-279), «actualmente la totalidad de los agentes implicados en el turismo han asumido y reconocido que la diversidad turística puede tener impactos negativos sobre el medio ambiente y que sus distintos impactos pueden controlarse».

A través de diferentes estudios realizados a nivel mundial, queda constatado que la actividad turística en general contribuye al deterioro medioambiental e incide de forma negativa en los problemas socioculturales y económicos de las diferentes zonas afectadas. Esta repercusión negativa está relacionada con las malas prácticas de ocio y otras actividades realizadas en zonas débiles o de especial protección, con el consumo incontrolado de recursos naturales o con la extralimitación de la capacidad de carga en épocas determinadas, factores que generan una degradación y un menoscabo de los espacios más sensibles.

A pesar de ello, es preciso advertir que no todas las acciones relacionadas con el turismo y el ocio contribuyen única y exclusivamente a la destrucción medioambiental. Afirmar esto sería erróneo. De hecho, también ha quedado demostrado que la actividad turística ha contribuido de forma positiva en muchas zonas a la sostenibilidad y a la conservación del medio ambiente, pues muchas veces la motivación principal de los viajes y de ciertas actividades es la recreación en diferentes medios o la contemplación de diferentes especies de fauna y flora. Este tipo de actividades hacen que los diferentes atractivos que conforman ciertos ecosistemas se mantengan protegidos, conservados y bajo una supervisión permanente para poder ser disfrutados por el conjunto de las personas que los visitan y admiran. De lo contrario, ciertos destinos, al deteriorarse, perderían su encanto y dejarían de ser demandados por la población turística, con lo cual asistiríamos a un cierto fenómeno de retroalimentación (véase figura 8.1).

Esta retroalimentación consigue conservar y mantener determinados ecosistemas librándolos de los deterioros físicos, sociales y culturales, mediante los beneficios que reporta una actividad turística controlada y motivada por el bien- 
estar medioambiental y poblacional de las áreas de destino. $\mathrm{Al}$ respecto, «existen muchos recursos biológicos que se protegen por el valor potencial que tienen para estas actividades económicas, y de aquí, precisamente, le viene el calificativo de turismo de naturaleza, al convertirse en uno de los instrumentos más importantes para la conservación del hábitat natural» (Martínez Quintana, 2009: 279).

Generalmente, en el turismo de naturaleza nos encontramos con una oferta turística bastante despolarizada en el espacio; no existe una concentración de los equipamientos turísticos en un mismo pueblo o ciudad; su disposición, por el contrario, es más bien dispersa. Se trata de un turismo activo que busca descubrir la realidad donde se inserta, tanto la cultural como la natural, y su práctica se lleva a cabo en áreas poco perturbadas por el hombre. Por ello es muy común la promoción de actividades lúdicas, deportivas, educativas, de entendimiento y de sensibilización cultural.

Figura 8.1. Sistema de retroalimentación de un espacio natural de interés turístico a través del turismo de naturaleza

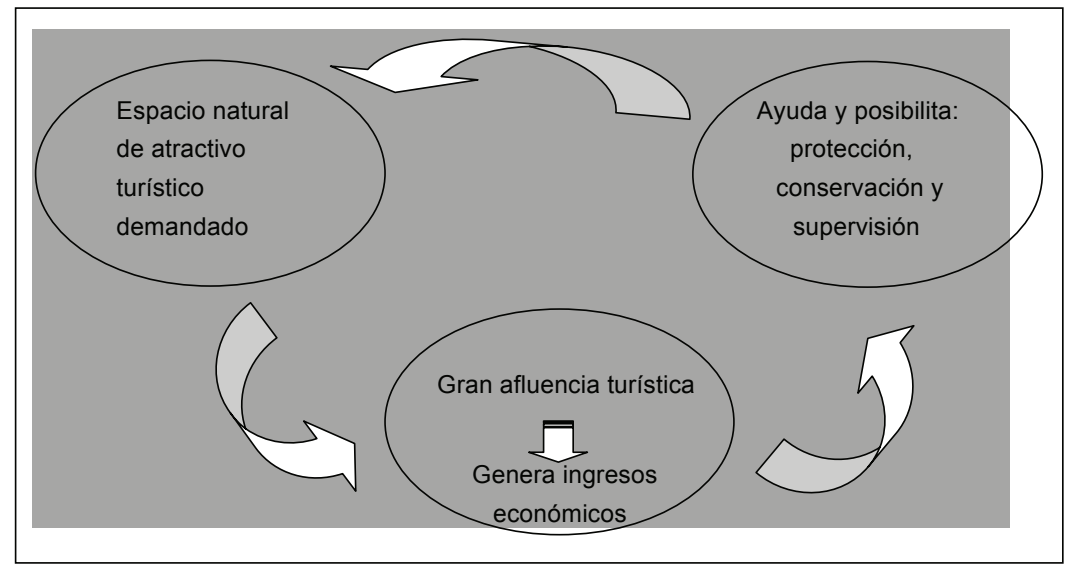

Fuenteः Elaboración propia.

El turismo en espacios naturales podría representar el mejor modelo de desarrollo sostenible del sector turístico, ya que conserva y protege los recursos naturales, valora las manifestaciones culturales locales e integra las poblaciones a la oferta, crea conciencia acerca de la protección del medio ambiente, y tiende a mejorar la calidad de vida de la población local del destino. Sin embargo, es una tipología que responde a un segmento de mercado muy específico, aún minoritario en llegadas e ingresos, a pesar de que el «turista de naturaleza» gasta, en promedio, más que turista común. A pesar de ello, existen opiniones, como las 
de Drumm y Moore (2002), que argumentan que el turismo de naturaleza es simplemente un turismo basado en la visita a recursos naturales y que está estrechamente relacionado con el ecoturismo, pero que no implica necesariamente la conservación o la sostenibilidad.

\section{Cuadro 8.1. Actividades económicas y sociales que deterioran el medio ambiente}

\begin{tabular}{|c|c|c|}
\hline $\begin{array}{l}\text { Actividades económicas } \\
y \text { sociales }\end{array}$ & $\begin{array}{l}\text { Relación con el } \\
\text { turismo y el ocio }\end{array}$ & $\begin{array}{l}\text { Contribución al } \\
\text { deterioro del } \\
\text { medio ambiente }\end{array}$ \\
\hline Caza y pesca. & $\begin{array}{l}\text { Incremento de la actividad } \\
\text { turística en determinadas áreas. }\end{array}$ & $\begin{array}{l}\text { Pérdida de la diversidad } \\
\text { biológica. }\end{array}$ \\
\hline $\begin{array}{l}\text { Producción y consumo de } \\
\text { energía. }\end{array}$ & $\begin{array}{l}\text { Incremento de la utilización de } \\
\text { diversos medios de transporte. }\end{array}$ & $\begin{array}{l}\text { Polución del aire. } \\
\text { Efecto invernadero. } \\
\text { Destrucción de la capa de } \\
\text { ozono. }\end{array}$ \\
\hline $\begin{array}{l}\text { Consumo de agua para } \\
\text { actividades humanas. }\end{array}$ & $\begin{array}{l}\text { Incremento del consumo de } \\
\text { recursos escasos durante la } \\
\text { temporada turística. }\end{array}$ & Escasez de recursos hídricos. \\
\hline $\begin{array}{l}\text { Uso del suelo y } \\
\text { reestructuración } \\
\text { medioambiental. }\end{array}$ & $\begin{array}{l}\text { Construcción de } \\
\text { infraestructuras: carreteras, } \\
\text { hoteles, parques, etc. }\end{array}$ & $\begin{array}{l}\text { Pérdida de la diversidad } \\
\text { biológica. } \\
\text { Erosión del suelo. }\end{array}$ \\
\hline $\begin{array}{l}\text { Desplazamiento y } \\
\text { concentración de personas } \\
\text { por diferentes actividades. }\end{array}$ & $\begin{array}{l}\text { Incremento del número de } \\
\text { personas en áreas turísticas } \\
\text { que originan más cantidad de } \\
\text { desechos. }\end{array}$ & $\begin{array}{l}\text { Contaminación de tierra, agua } \\
\text { y aire. }\end{array}$ \\
\hline
\end{tabular}

Fuente: Ballesteros, J. y Pérez Adan, J. (1997): Sociedad y medio ambiente, Trotta, Madrid.

La postura de Epler (2002) expone el surgimiento del ecoturismo a raíz de la práctica del turismo de naturaleza. Este tipo de turismo contribuye positivamente a la conservación del entorno en el país de destino turístico y en la población determinada de dicho destino, y consiste en viajar a entornos naturales vírgenes; interiorizar la experiencia que se obtiene al haber estado en entornos naturales puros y en contacto con gentes y culturas que se mantienen aisladas y que no son conocidas; impulsar la conservación de los recursos naturales, con lo que se garantiza un futuro sostenible, y ejercer una función educativa que conlleva la comprensión de los valores medioambientales y culturales de los lugares visitados.

Respecto a los impactos positivos, la actividad turística en general puede contribuir a la mejora del entorno medioambiental, a su preservación y a una mayor 
valoración de este, puesto que, en la actualidad, entre la población y los poderes públicos existe una mayor conciencia medioambiental y un mayor interés por la regeneración de espacios naturales, rurales y urbanos. Esto facilita la preservación de hábitats naturales, edificios, atractivos y lugares históricos, con el establecimiento de áreas protegidas (espacios protegidos, parques naturales, etc.) y una lucha más efectiva contra la contaminación.

En primer lugar, cabe señalar que el turismo puede servir de estímulo para adoptar medidas de mejora y conservación del medio ambiente. Es sabido que en gran cantidad de áreas turísticas las administraciones públicas han tratado de implementar medidas de planificación turística, que han llegado demasiado tarde, una vez que el entorno ya se ha degradado y tiene difícil recuperación. En segundo lugar, como actividades económicas que son, con gran dinamismo en los mercados a nivel mundial, el turismo y las actividades de ocio producen un incremento de los ingresos económicos que puede permitir realizar mayores inversiones en la conservación de los espacios naturales. El turismo genera directa e indirectamente un aumento de la actividad económica en los lugares visitados, fundamentalmente debido a la demanda de bienes y servicios que deben producirse y prestarse. Para hacerse una pequeña idea, la industria turística mundial contabilizó en 2010 la cantidad de 935 millones de turistas, un 6,7\% más que en 2009. Esa cifra supone 58 millones de turistas más que en 2009 y 22 millones más que en 2008, año en el que se registraron 913 millones de desplazamientos, el máximo nivel alcanzado hasta entonces. Estas cifras pueden dar una idea del volumen de ingresos generado por dichos movimientos en el pasado 2010, que superó los 693.000 millones de euros, lo que supone, en términos reales, una mejora del $5 \%$ respecto al año anterior.

Según los datos publicados por la Organización Mundial de Turismo (OMT), los ingresos por turismo internacional registraron un aumento inferior en dos puntos al del número de llegadas (del 7\%), lo que demuestra la estrecha relación entre ambos indicadores (desplazamientos e ingresos) y confirma que, en años de recuperación, las llegadas tienden a repuntar más rápido que los ingresos. Pese a que la gran mayoría de los destinos en todo el mundo presentó el año pasado datos positivos, la recuperación llegó a dos velocidades diferentes: más lenta en las economías avanzadas (un 5\%) y más rápida en las emergentes (un $8 \%$ ). En este escenario y por volumen de ingresos, España se mantiene en 2. ${ }^{\circ}$ puesto por detrás de Estados Unidos, y ocupa el $4 .^{\circ}$ puesto en volumen de llegadas de turistas (OMT, 2011).

Otros aspectos positivos se dan con respecto a la población autóctona de las áreas de destino turístico, ya que el turismo y las actividades que conlleva sirven 
para enriquecer su nivel social, cultural y económico debido a la comercialización de productos locales y al intercambio de ideas, de costumbres y de estilos de vida. La actividad turística también ayuda a sensibilizar a la población turística con la cuestión medioambiental, ejerciendo buenas prácticas, y a convencer a la población local para que proteja su entorno y establezca zonas de especial protección, como parques naturales, para la protección del medio ambiente.

Además, hay que señalar que, al igual que otras tipologías turísticas, allí donde se practique, el turismo de naturaleza generará empleo entre los residentes de las áreas turísticas y evitará el éxodo poblacional hacia otras zonas más desarrolladas en busca de trabajo. El turismo es uno de los pocos sectores intensivos en empleo, que abarca todo tipo de trabajos, desde los más cualificados a los menos, y es una de las pocas alternativas a la destrucción de empleo que se ha visto incrementada por el proceso de la globalización, los avances en las tecnologías y las comunicaciones y la reducción de la jornada laboral. Se trata de un sector donde conviven grandes multinacionales, pymes y microempresas familiares. El sector turístico proporciona empleo a alrededor de un $10 \%$ de la población activa del mundo, ya sea de forma directa o indirecta.

Finalmente, los impactos negativos muestran que las actividades relacionadas con el turismo y el ocio en los espacios naturales transforman el aspecto físico de las zonas turísticas, de forma que producen cambios irreversibles en el entorno y generan graves trastornos ecológicos, como la destrucción de ecosistemas, la disminución de la cantidad y calidad del agua, el empobrecimiento y la contaminación de los suelos. De esta forma, contribuyen a la extinción de múltiples especies de la fauna y de la flora autóctonas, a la depredación pesquera y a la contaminación marina. A ello se pueden unir los procesos de erosión y degradación del entorno a causa de dichas actividades, sufridos en playas, bosques, lagos, montañas y paisajes en general, que afectan también a la conservación y perpetuación de monumentos históricos, modos de vida, fauna diversa e incontables atractivos más que forman parte del espacio geográfico donde se desarrolla el turismo.

Por otra parte, es conveniente señalar que un crecimiento urbano excesivo y no integrado en el paisaje, en determinadas zonas, contribuye a una fractura de su equilibrio biológico, al tiempo que favorece la descomposición de actividades económicas tradicionales locales y colabora en un proceso de aculturación de las poblaciones de destino, con lo que se asume una pérdida de valores tradicionales y de diversidad cultural. Asimismo, favorece los procesos migratorios y genera fenómenos de crecimiento poblacional y urbano desordenado.

Asimismo, se puede argumentar que, en ocasiones, la afluencia tan numerosa de turistas en un área determinada coadyuva a un fenómeno de regresión del es- 
pacio natural, de forma que se destruyen los paisajes naturales; se incrementa la creación de espacios artificiales a base de infraestructuras como carreteras y vías de comunicación, zonas industriales, centros de ocio o residencias secundarias, y se reemplaza la vegetación autóctona por otro tipo de vegetación más exótica. En cuanto a los flujos turísticos, se observa que, a través de los diferentes medios de transporte, contribuyen al cambio climático, a las lluvias ácidas, a la destrucción de la capa de ozono y a la pérdida de biodiversidad, tanto de forma directa como indirecta, ya que todos los transportes por carretera, y principalmente los aviones como medio de transporte aéreo, son una de las más importantes causas de las emisiones de gases contaminantes.

Por último, es preciso señalar que la acumulación de personas en determinadas áreas que tienen una capacidad de carga limitada favorece la generación de una cantidad de residuos que puede provocar problemas de depuración de aguas residuales y de recogida de basura y una creación de vertidos incontrolados, entre otras consecuencias. Por otro lado, y debido a la estacionalidad de la demanda turística - sobre todo en actividades turísticas en entornos naturales-y, por ende, a la generación de temporadas baja y alta, se constata que hay periodos en que se multiplica el número de personas que se concentran en las zonas de destino, lo que, añadido a la coincidencia con el periodo crítico de muchos de los recursos (como los hídricos) presentes en el espacio natural, puede intensificar el desgaste medioambiental.

Las actividades de ocio y turismo también producen una sobrecarga de la infraestructura en los lugares de destino, que se manifiesta cuando la intensidad de las visitas supera la capacidad de la infraestructura prevista. Esto, a su vez, trae consigo apreciables niveles de contaminación y posibles consecuencias en la salud de las personas. En definitiva, el turismo contribuye a una segregación de residentes locales; es decir, a la separación de las áreas turísticas del resto del área local, lo que conlleva, en ocasiones, a una segregación social.

Hasta aquí se puede convenir en que las actividades de ocio y turismo en la naturaleza generan, como se ha visto, importantes impactos positivos y negativos. Ciertamente, la preocupación existente ante estos últimos se ha extendido al conjunto de los actores participantes en la industria turística, desde productores e intermediarios hasta los propios consumidores. Pero también hay que decir, y sin ánimo de restarle importancia a las consecuencias muchas veces irreversibles de la actividad turística, que existen otras muchas actividades económicas realizadas en la actualidad que causan efectos negativos de mayor repercusión que los del turismo, como la extracción de petróleo, la tala de árboles, las actividades mineras o las diversas industrias contaminantes. 
La cuestión es, como afirman algunos autores, que a ese proceso de sensibilización creciente que se está introduciendo en la sociedad sobre las catástrofes medioambientales y sobre el deterioro de los recursos naturales existentes hay que anexarle, para poner fin a las malas prácticas en un turismo no controlado y no planificado, una regulación fiscal sobre las actividades que se desprenden del ocio y del turismo. En este sentido, y para establecer una mejor planificación de los usos turísticos y reducir los efectos negativos que estos generan, es necesario aumentar la fiscalidad sobre ciertos recursos como el uso de combustibles, necesarios para los transportes que facilitan los desplazamientos de mercancías y personas; el uso de suelo para la edificación de viviendas, hoteles, centros comerciales y de ocio, etc.; el uso del agua, o la generación masiva de residuos en épocas de elevada concentración turística.

\section{Desarrollo y contribución del turismo sostenible a la conservación del medio ambiente}

Indudablemente, el núcleo básico para el desarrollo y la contribución a la conservación del medio ambiente se encuentra en el denominado «turismo sostenible», que se impone a finales de la década de 1980, dadas las condiciones de impacto ocioturísticas importantes que se empiezan a detectar. En consecuencia, resulta imprescindible implementar el turismo sostenible y conocer sus aportaciones, así como conocer las motivaciones para desarrollarlo en las zonas de destino ocioturísticas.

A lo largo de la historia, el ser humano ha ido haciendo uso y explotación del medio ambiente de forma abusiva, lo que ha producido un menoscabo de los recursos naturales y medioambientales del planeta. Desde diferentes posiciones se ha intentado reconducir el equilibrio perdido con la naturaleza y la Comisión Mundial sobre el Medio Ambiente y el Desarrollo ${ }^{1}$ plantea la puesta en marcha de un desarrollo sostenible como «un tipo de desarrollo cuyo principio general es la satisfacción de las necesidades humanas del presente sin comprometer la capacidad de las futuras generaciones para satisfacer las suyas propias». En este sentido, las Naciones Unidas han sido pioneras al tratar el tema, centrándose inicialmente en el estudio y la utilización de los recursos naturales y en la lucha porque los países —en especial, aquellos en vías de desarrollo- ejercieran el control de sus propios recursos naturales. Por lo tanto, para la sostenibilidad de

1 Esta definición fue empleada por primera vez en 1987 en la Comisión Mundial del Medio Ambiente de la ONU, creada en 1983. 
los territorios, se considera eminentemente necesario un desarrollo del territorio equilibrado, integrado y acorde con su medio ambiente.

Las actividades que comporta el turismo, hasta hace pocos años, se han visto como oponentes inconscientes del medio natural a través de la generación de efectos adversos que implicaban en sí mismas, como la construcción de edificaciones que impiden ver el mar o degradan paisajes interiores y costeros, la producción de residuos humanos procedentes de complejos y centros turísticos o la emisión de salidas de gases de automóviles y de ruidos que contaminan la pureza del aire y el agua (dos de los recursos principales del turismo).

Con el desarrollo de la sociedad y el aumento del nivel de vida, hay autores, como Mc Nelly (1995), que indican que, a medida que aumenta la población humana, las presiones de la vida urbana incitan al individuo a buscar la soledad de la naturaleza y, por lo tanto, crece el número de visitantes a las zonas rurales, parques y áreas protegidas, con lo que las tipologías turísticas que utilizan como entorno los espacios naturales cada vez están siendo más demandadas. Al desarrollo sostenible del turismo va indisolublemente ligado el concepto de capacidad de carga referido a la capacidad turística o capacidad de acogida de visitantes por parte del lugar turístico de destino. (Mathieson y Wall, 1982; McIntyre, 1993; Crosby y Moreda, 1996). Este concepto hace referencia al uso máximo que puede hacerse de un lugar sin causar deterioro de sus recursos, la insatisfacción de los visitantes ni la generación de impactos adversos sobre la sociedad, la economía o la cultura locales.

Las nuevas tendencias del mercado indican que cada vez se valora más la calidad ambiental y la autenticidad de las propuestas turísticas. Esto es crecientemente captado por las propias autoridades, empresarios y actores locales de sitios turísticos que comienzan a preocuparse por este tema en la medida que el turismo de calidad estimula las economías locales, crea empleo, genera intercambio de divisas, y mejora las infraestructuras que son utilizadas por toda la población.

En esta línea, la Organización Mundial de Turismo (OMT) ha reconocido que el turista se está sensibilizando cada vez más por los aspectos ambientales. Este factor no solo genera una diversificación motivacional, sino que es un valor muy apreciado en gran parte de la población y se incluye en las grandes tendencias del mundo actual. Por ello, se puede evidenciar que no solo ha aparecido un conjunto de turismos específicos que tienen como base el medio ambiente y los recursos naturales, sino que cualquier actividad turística, sea de naturaleza o no, tiene que considerar su aspecto ambiental. Desde esta perspectiva se pueden distinguir cuatro maneras distintas en las que interviene el medio ambiente en la oferta turística, que son: 
+ Cuando el medio ambiente es la motivación exclusiva, lo que ha producido las tipologías de turismo de naturaleza y ecoturismo (tipología que compatibiliza el disfrute de la naturaleza y el respeto al equilibrio del medio ambiente.)

- Cuando se tiene en cuenta el medio ambiente, como principal factor pero no único. Aquí cabría resaltar el turismo rural, incluyendo en este caso el concepto ambiental desde la antropología.

- Cuando el aspecto ambiental tiene un carácter complementario. Aquí, el entorno se convierte en un espectáculo, con unas limitaciones temporales y espaciales (parques temáticos, zoos, jardines botánicos, acuarios, etc.).

- Cuando la conservación del medio ambiente forma parte, de algún modo, de los productos y servicios turísticos concretos: transportes no contaminantes hoteles con energía alternativa, restaurantes con productos ecológicos, etc.

El «turismo sostenible» puede definirse como aquel que no compromete la conservación de los recursos naturales y culturales sobre los que se sustenta y que, por tanto, reconoce explícitamente las necesidades de protección del medio ambiente. Comprende todas las formas y destinos, las áreas rurales y las ciudades, el turismo de masas y los viajes individuales o en pequeños grupos. Es básicamente un turismo que integra abiertamente la capacidad de desarrollo del medio receptor de una forma cohesionada entre todos los interlocutores bajo una versión de incremento medido y equilibrado. En este sentido, Martínez Quintana (2009) explica que el turismo sostenible desde la perspectiva del concepto de sostenibilidad se centra profundamente en el ámbito medioambiental, y por ello es necesario hacer un uso óptimo de los recursos ambientales, con un respeto absoluto hacia la autenticidad de las comunidades anfitrionas, y comprometiéndose con la viabilidad a largo plazo de sus actividades económicas. Para el desarrollo de la actividad turística de una manera sostenible, "en consecuencia, se requieren los cuatro elementos de la Responsabilidad Social Empresarial: responsabilidad económica, legal, ética y altruismo-compromiso con la sociedad" (Martínez Quintana, 2009: 273).

Estos idearios se sustentan en una gran cantidad de documentos que se han venido elaborando con el paso de los años desde las más altas instancias responsables y coordinadoras del turismo a nivel mundial. De este modo, «la responsabilidad y sostenibilidad del turismo tienen sus orígenes en la Carta de Turismo Sostenible (Conferencia Mundial del Turismo Sostenible, celebrada en Lanzarote, Islas Canarias, en 1995), que se asentó en los documentos de Manila, Sofía, 
La Haya, la Declaración Universal de los Derechos Humanos y la Declaración de Río sobre el Medio Ambiente y Desarrollo, cuyos principios fundamentales ubicaban el desarrollo turístico en la sostenibilidad, desde una visión integral que incorporase en todo su ciclo y a largo plazo la viabilidad ecológica y económica, y la equidad ética y social de las comunidades locales» (ibidem, 2009: 273).

No obstante y según se desprende de las declaraciones del anterior director de Desarrollo Sostenible de la $\mathrm{OMT}^{2}$, con frecuencia existe cierta confusión sobre el concepto de sostenibilidad cuando se aplica al turismo. Algunos autores y, sobre todo, algunas empresas turísticas tienden a equiparar el concepto de turismo sostenible con el ecoturismo, lo cual es incorrecto. En esta línea se han detectado algunas confusiones donde se asocia el concepto de ecoturismo con el de turismo sostenible, cuando esta tipología es mucho más global y general y abarca innumerables tipologías turísticas. También incluso, a menudo, ha sido confundido con el turismo de naturaleza cuando no debería ser así, ya que esta última tipología «se basa en elegir la naturaleza principalmente, y se constituye en la motivación principal del viaje para el disfrute del ocio y tiempo libre» (ibidem, 2009: 277). Por lo tanto, como señala Yunis (2004), el concepto de sostenibilidad y los principios que implica se deben aplicar a todas las formas de turismo, ya sea a la motivación del viaje, al tipo de destinos o a las actividades que el turista realice en ellos.

Este autor indica que, para alcanzar un desarrollo sostenible de la actividad turística, se requiere normalmente satisfacer una serie de condiciones, que permiten el equilibrio entre las dimensiones ambientales, económicas y socioculturales. A saber:

- Se hace necesaria la articulación de una política de turismo a tres niveles: nacional, regional y local; el turismo no puede seguir creciendo de forma desordenada o anárquica, con acciones espontáneas por parte de actores que operan en un marco totalmente desregulado y descoordinado.

- La política de turismo debe ser el resultado de un proceso participativo donde todas las partes interesadas y especialmente la comunidad local sean consultadas.

- Se requiere adoptar un enfoque integrador, en el cual el turismo sea parte de un desarrollo global de la localidad o el país, y donde las infraestructuras propiamente turísticas sean planificadas en conjunto con los requerimientos de las infraestructuras generales, de la formación de recursos humanos, de los transportes, etc., así como con el marco institucional adecuado.

2 Eugenio Yunis Ahués, director de Desarrollo Sostenible, Organización Mundial del Turismo, de 1997 a 2007. 
- Las técnicas de evaluación de impacto ambiental se deben aplicar a todos los proyectos turísticos y desde su etapa inicial, antes de implementarlos. Debe asegurarse que los costos de evitar ciertos efectos potenciales negativos sean tomados en cuenta en los análisis de preinversión.

- La gestión de los destinos y de las empresas turísticas que allí operan deben tener en el centro de sus preocupaciones al medio ambiente natural, a la cultura local y a los residentes locales; ninguna de las acciones que realicen las empresas turísticas para satisfacer a los turistas debe ir en detrimento de la localidad.

- Los límites al crecimiento del turismo (expresados en diferentes indicadores como, por ejemplo, la capacidad de carga) deben ser respetados de igual manera por autoridades públicas y empresas privadas y turísticas.

Según asume la OMT (Yunis, 2004), el principal reto que enfrenta el sector turístico en todo el mundo, para alcanzar un nivel más alto de sostenibilidad, es incrementar la aplicación de los conocimientos existentes en la planificación real y en el desarrollo de los destinos turísticos por parte de las administraciones públicas y en el funcionamiento cotidiano de las empresas turísticas. Para ello se proponen las siguientes medidas:

- Adaptar los conocimientos metodológicos y tecnológicos existentes a las situaciones específicas de cada región, país, provincia, localidad o centro de atracción turística.

- Otorgar a la administración de turismo, tanto nacional como local, suficiente autoridad y capacidad técnica.

- En el caso de no existir una legislación exhaustiva a disposición de la administración, dotarla de los instrumentos necesarios para controlar y para supervisar el cumplimiento de las normas existentes.

- Procurar un apoyo financiero a todas las empresas que se dedican a la actividad turística para que puedan aplicar métodos de gestión sostenible o introducir en sus infraestructuras tecnologías más modernas y respetuosas con el medio ambiente.

- Propiciar una mayor coordinación por parte de todos los actores que están involucrados en la actividad turística. La coordinación y eventual integración de políticas sectoriales en un mismo territorio; la coordinación de la asistencia técnica y financiera, y el diálogo y la concertación entre el Estado y los empresarios, así como entre estos y las instituciones de formación, son factores fundamentales para poder garantizar unos resultados coherentes y un desarrollo sostenible del turismo. 
En la línea de estas propuestas, hay autores que han señalado la decidida importancia que tiene aplicar métodos y técnicas concretas sobre indicadores de calidad medioambiental en zonas turísticas sostenibles, para asegurar la competitividad atendiendo a los principios de sostenibilidad. Así, Boyra Amposta introduce una clasificación de indicadores básicos y específicos para los destinos turísticos que han sido elaborados a partir de los trabajos de Ayuso y Fullana (2001) y se pueden resumir en los diez siguientes:

1. Protección del lugar. Medición categoría de protección del lugar según el índice de la Unión Internacional para la conservación de la naturaleza (IUCN).

2. Presión. Número de turistas que visitan el lugar (por año y mes).

3. Intensidad de uso. Temporada alta (personas/hectárea).

4. Impacto social. Proporción de turistas respecto a los residentes locales (temporada alta).

5. Control del desarrollo. Existencia de procedimientos de revisión ambiental o controles oficiales del desarrollo del lugar y de intensidad de uso.

6. Tratamiento de residuos. Porcentajes de aguas residuales que se someten a tratamiento (también pueden tomarse como indicadores los límites de otras capacidades infraestructurales del lugar como, por ejemplo, suministro de aguas o basuras).

7. Proceso de planificación. Existencia de un plan regional organizado por la región del destino turístico.

8. Ecosistemas críticos. Número de especies poco frecuentes o en peligro.

9. Satisfacción del consumidor. Grado de satisfacción de los visitantes (basado en un cuestionario).

10. Satisfacción de la población local. Grado de satisfacción de la población local (basado en un cuestionario).

Hay que señalar, además, que el desarrollo de políticas para favorecer un turismo sostenible que sea responsable y respetuoso con el medio ambiente no ha sido una cuestión pasajera, sino que sigue en aumento; así, no cejan las iniciativas y los trabajos para continuar con esta dinámica que a la vez se va intensificando con el paso del tiempo. El escepticismo sobre las repercusiones del turismo en el medio ha desaparecido y parece que es algo muy visible y que preocupa cada vez más al conjunto del planeta. Una muestra de que se sigue trabajando para aminorar el deterioro medioambiental ocasionado por las actividades turísticas y de ocio ha sido la reciente creación de la Asociación Mundial para el Turismo Sostenible a principios del año 2011. Con ella, el turismo sostenible ha recibido un gran impulso y se ha producido un proceso de unificación de todos los in- 
teresados de la industria para influir en políticas, participar en el desarrollo de proyectos y proporcionar una plataforma de comunicación global.

Esta nueva asociación se estableció durante su primera Asamblea General anual celebrada en Costa Rica, auspiciada por el Ministerio de Turismo de Costa Rica y apoyada por los gobiernos francés y noruego, junto con el Programa de las Naciones Unidas para el Medio Ambiente (PNUMA) y la Organización Mundial del Turismo (OMT). Hasta ahora, está formada por 18 gobiernos nacionales, cinco organizaciones de las Naciones Unidas, la Organización para la Cooperación y el Desarrollo Económicos (OCDE), 17 organizaciones internacionales y de negocios, así como 16 organizaciones no gubernamentales que demostrarán su compromiso con la promoción de la sostenibilidad en el sector turístico. Por ello, su presidente Gérard Ruiz ha manifestado en declaraciones a prensa que «el amplio alcance geográfico de la Asociación, así como la profundidad de la experiencia de sus miembros, le permitirá adaptar, replicar y ampliar proyectos exitosos de cualquier socio en otras regiones, con la participación de los sectores público, privado y consumidor, la identificación de oportunidades de proyectos y creación de oportunidades de financiación e información sobre las políticas que beneficiarán el desarrollo y la promoción de la sostenibilidad en el turismo».

El secretariado de esta innovadora asociación mundial se encuentra, con la División de Tecnología, Industria y Economía (DTIE), en París, Francia, y su principal objetivo será posicionar el turismo en una vía sostenible a escala mundial. Además, servirá como foro dinámico y actualizado donde los países que están interesados en el turismo sostenible puedan aprender de los esfuerzos exitosos de los otros miembros y obtener asistencia técnica. También tendrá como finalidad promover el diálogo constante y el intercambio de experiencias, y buscar soluciones a los problemas comunes en el sector del turismo.

El punto de partida de esta asociación mundial es que, puesto que el turismo es una de las industrias más grandes del mundo y es una fuente de ingresos importante para los países en vías de desarrollo, existe el convencimiento de que, si no se maneja bien, el turismo también puede poner en peligro los recursos naturales de un país a causa de una mayor demanda en el consumo de agua, energía, y generación de desechos, llevando así a la degradación del medio ambiente y a un impacto negativo en las poblaciones locales. En palabras del actual director de Desarrollo Sostenible en la Organización Mundial del Turismo (OMT), Luigi Cabrini, «el sector del turismo ha sido cada vez más reconocido como un motor clave para el crecimiento económico, especialmente en los países en desarrollo y menos desarrollados. No solo es responsable de una proporción importante del PIB mundial (5\%) y del empleo (6-7\%), sino que es también una fuente impor- 
tante de inversión extranjera alcanzando hasta el 30\% de las exportaciones de servicios del mundo. El número de llegadas de turistas internacionales se espera que llegue a 1,6 billones en $2020 »$.

La preocupación por la sostenibilidad en el turismo surge desde el momento en que existe una clara conciencia de los impactos que esta actividad genera en el medio ambiente. Su estrecho contacto con la naturaleza lleva a una imbricación del medio ambiente y el turismo. Según Merino y Nieto (en Ballesteros y Pérez Adán, 1997: 363), existe una serie de actividades económicas y sociales que deterioran el medio ambiente y tienen una vinculación estrecha con el turismo (véase cuadro 8.1).

Es innegable que asistimos a un cambio importante de la demanda turística en la población debido a la crisis sufrida por el modelo de turismo convencional y a la preocupación creciente de las poblaciones de los países desarrollados por mejorar su calidad de vida. En realidad, este cambio viene implementado por la gran transformación social derivada de la crisis de civilización que asume como rasgos distintivos una mayor autonomía e individualismo, un culto exacerbado al hedonismo y un gran interés por la vuelta a la naturaleza; es decir, una recuperación de lo individual y auténtico en detrimento de las cuestiones materiales y colectivas propias de una sociedad que, hasta ahora y desde el nacimiento del turismo de masas, ha venido proyectando sus servicios y productos de consumo como elementos estandarizados parejos a los modelos de producción.

No obstante, hay que señalar que, en esta transformación de la sociedad contemporánea, el deterioro del medio ambiente propiciado por las actividades turísticas y de ocio ha jugado un papel fundamental. Es innegable que cuestiones como la creciente contaminación de la atmósfera, de los suelos y del agua; el decremento y la desaparición de múltiples especies de la flora y de la fauna; la destrucción de la capa de ozono, y otras cuestiones que afectan al medio ambiente, en conjunto y a medio y largo plazo, se vislumbran como amenazas para la supervivencia del ser humano, pero en la actualidad y a corto plazo se traducen en una pérdida de la calidad de vida de las personas.

Dichas cuestiones han sido determinantes para que en los últimos veinte años se hayan creado movimientos sociales conservacionistas, ecologistas y ambientalistas de diversa índole con el objetivo de que entre los gobiernos y las poblaciones en general se busquen y adopten nuevas formas de desarrollo (donde se incluye el desarrollo del turismo) que se adecuen, por una parte, a los requerimientos de transformación y aprovechamiento de la naturaleza y, por otra, a la necesidad de su conservación como condición para preservar la propia existencia humana. Es en este marco en el que surge el concepto de «desarrollo sostenible» y con ello las 
nuevas tipologías turísticas basadas en la sostenibilidad del medio como factor determinante.

Es preciso indicar que la creciente preocupación ambiental determinó sobremanera el surgimiento de la corriente turística que tiene como destino el medio natural, y que es la corriente de mayor crecimiento a nivel mundial. Así, actualmente no solo se habla de convertir el turismo en general en una actividad sostenible, sino que se hacen referencias a algunas corrientes específicas del turismo que están relacionadas con el desarrollo sostenible, como el turismo ecológico, el agroturismo, el turismo verde, el turismo activo, el turismo de naturaleza y el ecoturismo, y que abogan específicamente por el mantenimiento de la sostenibilidad. $\mathrm{Al}$ respecto de esta consideración, es relevante señalar que un informe realizado por el Instituto Worldwactch (Zoe, 2005) distingue ocho modalidades diferentes de turismo que poseen bastante semejanza, aunque con matices, y que están relacionadas con la sostenibilidad y el medio ambiente:

- Turismo de aventura. Forma de turismo basado en la naturaleza que contiene un componente de riesgo, y requiere niveles altos de esfuerzo físico y una habilidad especializada.

- Ecoturismo. Viaje responsable a áreas naturales que conserva el ambiente y mejora el bienestar de la gente del lugar.

- Geoturismo. Turismo que sostiene o aumenta el carácter geográfico de un lugar - el ambiente, la herencia, la estética, la cultura y el bienestar de sus residentes-.

- Turismo masivo. Turismo a gran escala, típicamente asociado con hoteles de «mar, arena y sol», con características como la propiedad trasnacional, el beneficio económico directo mínimo a las comunidades de destino, la temporada y los viajes organizados.

- Turismo basado en la naturaleza. Cualquier forma de turismo que depende del ambiente natural para sus atracciones o sitios.

+ Turismo propobres. Turismo que tiene un resultado positivo para las personas pobres.

- Turismo responsable. Turismo que lleva al máximo los beneficios a las comunidades locales, minimiza los impactos negativos sociales o ambientales y ayuda a las gentes del lugar a conservar las culturas frágiles, los habitantes y las especies.

- Turismo sostenible. Turismo que satisface las necesidades de los turistas y las regiones turísticas, al tiempo que protege y hace crecer las oportunidades para el futuro. 
Por otra parte, y al hilo de las motivaciones para el ejercicio de un turismo sostenible, hay que tener presente que una utilización sostenible de los recursos en una zona concreta la provee de una serie de ventajas competitivas que es conveniente considerar:

- Facilita el cumplimento de la normativa vigente. En los últimos años las normativas, a diversas escalas, relacionadas con la necesidad de preservar ciertos recursos, se han desarrollado y, cada vez más, se hacen cumplir.

- Permite mejorar la posición económica. Es evidente que un municipio con problemas ambientales resulta cada vez menos atractivo para los turistas y para los inversores.

- Genera nuevos yacimientos de empleo. Se hace necesario crear estaciones depuradoras, realizar recogida selectiva de residuos sólidos, desarrollar la industria de reciclaje, etc.

- Mejora la imagen de marca del propio municipio a través del marketing ecológico, que es reaprovechado y reintroducido en la propia oferta.

- Promueve un proceso, aunque lento, de educación ambiental, de mejora de la sensibilidad, tanto de los residentes como de los visitantes (se produce una retroalimentación).

Más allá de todo esto, se entiende que la preservación del medio ambiente ha de ser considerada como un valor en sí mismo.

\section{La gestión de los espacios rurales y naturalesł el turismo rural y el turismo activo}

Los espacios rurales y naturales constituyen el territorio básico de implementación del ocio y el turismo, donde lo local adquiere un gran protagonismo. Nos situamos, pues, en la base territorial del producto turístico en el que se produce y consume a la vez, y surge una tipología de turismo con unos efectos económicos y sociales.

Según manifiestan en sus análisis especialistas como Blázquez (2010), el turismo ha adquirido gran importancia en la primera década del siglo xxI, al haberse convertido en una de las actividades de servicios más rentables, que adquiere relevancia precisamente en los espacios rurales y naturales. Ahora bien, la introducción en el área rural no está exenta de dificultades y de obstáculos, dada la visión negativa que se ha hecho patente en las zonas rurales respecto a las repercusiones de su implantación (muchas personas, atascos, ruidos, suciedad, contaminación, etc.). 
Las dificultades del desarrollo del turismo en los espacios rurales y naturales vienen ocasionadas por la inevitable transformación que supone, y que se palia a su vez, por los cambios que se están dando en los últimos años en las estructuras productivas del campo. Si nos aproximamos al ámbito europeo encontramos varios factores que dificultan el desarrollo, como las peculiaridades que pueda presentar un medio físico natural desfavorable para un agricultura competitiva, las dificultades para integrarse en los sistemas de actividades secundarias y terciarias o unas deficientes comunicaciones que sitúan a las zonas rurales en condiciones de aislamiento; todo ello en áreas especializadas en la agricultura y la ganadería tradicionales, que han sido actividades muy beneficiosas para el mantenimiento de los paisajes europeos.

Blázquez (2010: 956) recopila del seminario «Situation et perspectives de l'Europe rurale» los elementos que intervienen en la mayoría de las zonas rurales en desarrollo:

- Declive en el empleo en el sector agrícola e importancia económica relativa de la producción alimentaria.

- Mundialización de los elementos clave de la economía.

- Introducción y propagación de las nuevas tecnologías, particularmente de las tecnologías de la información y de las comunicaciones, así como de la biotecnología.

- Los cambios demográficos desembocan en el envejecimiento de la población y en el incremento de las relaciones de dependencia.

- Movilidad personal creciente, a través de las migraciones cotidianas, las migraciones definitivas, el turismo y las actividades de ocio.

- Emergencia de una nueva utilización del espacio rural y de nuevas demandas sociales en cuanto al uso del suelo y del paisaje.

- Emergencia de nuevos ganadores y perdedores como consecuencia de los procesos de cambio.

- Emergencia del medio ambiente como una potente fuerza política y ética.

- Establecimiento de un nuevo orden mundial o ideología de «mercado libre».

- Búsqueda de nuevas formas de gestión, con más apoyo a la participación de conjunto de la población, aunque se mantiene una fuerte participación de la administración.

Las tipologías de turismo en estos espacios son las siguientes: turismo rural, agroturismo, turismo de naturaleza, ecoturismo, turismo sostenible, turismo responsable, turismo activo, turismo de aventura y turismo deportivo. Blázquez 
(2010) clasifica esta amalgama de actividades según la tipología de turismo, la localización, las características y las actividades que lleva a cabo:

- Turismo rural. Localización: Espacios rurales. Características: Predominio del sector de alojamiento. Oferta muy heterogénea. Actividades con fuerte motivación cultural (enografía, historia, arquitectura, gastronomía local). Diferentes grados de participación del turista en las actividades, desde muy bajo (ocio pasivo) a muy alto (ocio activo). Diversidad en las legislaciones autonómicas. Actividades: Alojamiento. Restauración. Visitas al patrimonio local. Visitas a museos y centros de interpretación. Talleres (elaboración de quesos, jabón, miel, esencias, etc.). Participación en actividades agropecuarias. Visitas zonas de baño. Descanso/relax.

- Turismo de naturaleza de interés específico. Localización: Espacios naturales, especialmente espacios naturales protegidos. Caracteristicas: El conocimiento de la naturaleza y la interpretación del patrimonio son sus principales motivaciones. Oferta heterogénea con fuerte presencia de la administración pública. Combinación de actividades turísticas y educativas. Dificultades para encontrar producto turístico exclusivamente de turismo de naturaleza. Diversidad de acepciones: ecoturismo, turismo de observación de fauna, turismo verde, etc. Carencia de legislación que aclare el marco de actuación de las empresas del sector. Fuerte interés de turistas extranjeros por la oferta española. Actividades: Visitas guiadas. Observación de la naturaleza (observación de aves, observación de cetáceos). Fotografía de la naturaleza. Ecoturismo científico. Actividades de educación ambiental.

- Turismo activo. Localización: Espacios naturales (en muchas ocasiones en espacios naturales protegidos, si la legislación lo permite) o espacios rurales. Características: Oferta muy heterogénea. Actividades deportivas en el medio natural. En todos los casos, participación activa por parte del turista (ocio activo). Diferente grado de sensación de riesgo en función de la actividad elegida. Diversidad en las legislaciones autonómicas. Falta de marco legislativo en varias comunidades autónomas. Fuerte especialización territorial en función de los recursos disponibles. Continua aparición de nuevas empresas y actividades. Compleja relación entre las actividades y la legislación ambiental. Actividades: Dada la gran variedad de actividades, habitualmente se dividen según el medio en que se realizan: tierra, nieve, agua o aire. Las actividades más extendidas y distribuidas prácticamente por todo el territorio español son, por este orden: sende- 
rismo, bicicleta de montaña y rutas a caballo. En el apartado dedicado al turismo activo encontramos una relación con las más representativas.

En este nuevo concepto de hacer un turismo diversificado en espacios rurales y naturales, los tipos de turismo que tienen más consistencia son el turismo rural, el turismo de naturaleza y el turismo activo, mientras que los restantes aparecen de manera colateral y complementaria a estas tres variantes e interactúan y se combinan según las motivaciones de los turistas y viajeros, y las ofertas y equipamientos propios del territorio seleccionado. Por tanto, en la modalidad de «otros turismos en la naturaleza» se sitúan los siguientes: agroturismo, ecoturismo, turismo sostenible, turismo responsable, turismo de aventura y turismo deportivo (véase figura 8.2).

Así pues, el agroturismo es una modalidad que se basa en el alojamiento en casas rurales y en la que los visitantes y turistas pueden participar en las tareas agrícolas, artesanales, ganaderas, talleres florales, etc. Son alojamientos con instalaciones agropecuarias, granjas, corrales, huertos y demás, que combinan el ocio y la recreación de actividades agrícolas y artesanales típicas de la zona con el descanso, el disfrute de la naturaleza y la realización de las actividades que se prefiera. En España el primer establecimiento se crea en el País Vasco en 1988. Su representación porcentual todavía es baja, a diferencia de lo que sucede en países de Centroamérica o Sudamérica, o en Francia, donde esta modalidad cuenta con una buena representación.

\section{Figura 8.2. Interacción de turismos en espacios rurales y natural}

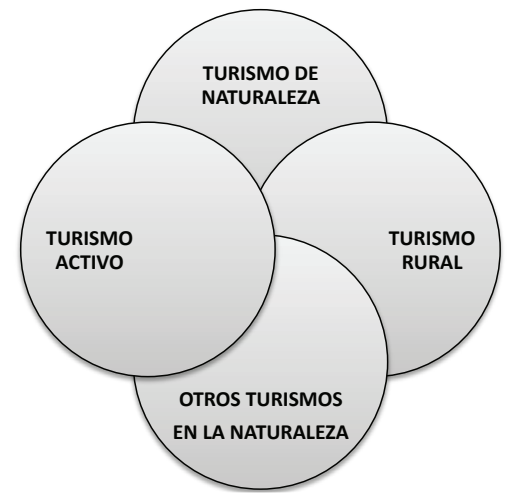

Fuente: elaboración propia en orden a la interacción de turismos en áreas rurales y naturales con la sostenibilidad. 
El ecoturismo surgió en un principio en el ámbito circunscrito a los espacios naturales protegidos. Conforme se fue desarrollando, el concepto se amplió para dar cuenta de cualquier actividad que tuviese por objeto concreto la contemplación y el disfrute de los recursos naturales y culturales de un territorio específico. Más tarde, se incorpora una filosofía que da cuenta del modelo de gestión del turismo y las repercusiones que pueda tener no solo para la contemplación y disfrute del hábitat natural, sino también para las poblaciones anfitrionas y los mismos visitantes. Aquí se alinean el ecoturismo, el turismo sostenible y el turismo ambientalmente responsable, que tienen una misma finalidad: representar modalidades ocioturísticas no depredadoras o extractivas, donde las gentes locales alcanzan la categoría de actores participativos y no decorativos.

Respecto al turismo sostenible, alude a los impactos que recibe el territorio rural y natural y pretende reducirlos o amortiguarlos. Puede ser cualquier modalidad de turismo que fabrique sus productos sin repercutir negativamente no solo al medio ambiente, sino también a las poblaciones locales que habitan y subsisten en el hábitat. Es un turismo que satisface las necesidades de los turistas y las regiones turísticas mientras protege y hace crecer las oportunidades.

El turismo responsable es una tipología que lleva al máximo los beneficios a las comunidades locales, minimiza los impactos negativos sociales o ambientales y ayuda a la gente del lugar a conservar las culturas frágiles, a sus habitantes y a las especies que allí habitan. De manera holística tiene en cuenta los contextos naturales, los socioculturales, los económicos y los políticos de un destino ocioturístico para minimizar los impactos negativos e incrementar el beneficio al máximo. La innovación que comporta esta modalidad es que el turista debe intervenir en el proceso, ya que debe implicarse y actuar a través de su comportamiento social.

Los elementos que intervienen en la conformación del turismo responsable se concretan en cuatro principalmente: equidad social, respeto por la cultura, respeto por el medio ambiente y viabilidad económica. En este sentido, es un turismo completo y abarca más elementos de intervención que los anteriores, ya que implica prácticamente a todos los actores sociales y a la totalidad de las infraestructuras naturales elaboradas por los técnicos del sector.

Finalmente, el turismo de aventura comprende los productos que se centran en el turismo activo y que constituyen partes de un programa en un destino de ocio y turismo catalogado como «exótico». La linde entre un turismo y otro no se percibe en destinos de Centroamérica y Sudamérica, que los engloban en un todo. En cuanto al turismo deportivo, puede relacionarse tanto con el de aventura como con el activo, al ser los tres muy similares. La única diferencia radica en la participación de los sujetos, que puede ser activa o pasiva. Todas estas tipologías 
de turismo en su conjunto contribuyen al desarrollo y mantenimiento del turismo en la sostenibilidad.

\section{Referencias bibliográficas}

Ayuso, S. y Fullana, P. (2001). Turisme sostenible. Barcelona: Departament de Medi Ambient. Generalitat de Catalunya.

Ballesteros, J. y Pérez, J. (1997). Sociedad y medio ambiente. Madrid: Trotta.

Blanco, R+y Fernández, F. (2007). «Formas de socialización y perspectivas de los jóvenes ante el desarrollo rural», en José Antonio Pérez (coord.). Los intangibles en el desarrollo rural. Cáceres: Universidad de Extremadura, Servicio de Publicaciones.

Blázquez, J. (2010). «Turismo en espacios rurales y naturales» en Aranda, A.; Delgado, L. M y De Juan, J. M. (coords.). Turismo: una visión global. Pamplona: Aranzadi, Thomson Reuters. Pp.953-1015.

Chafe, Z. (2005). «Interest in Responsable Travel Grows, Vital Signs» (The World-watch Institute), p. 101, which sources: Merriam - Webster Dictionary, National Geographic Traveler, TIES, World Tourism Organization, ProPoor Tourism, Encyclopedia of Ecotourism and Responsibletravel.com.

Crosby, A. y Moreda, A. (1996). Elementos básicos para un turismo sostenible en las áreas naturales. Madrid: Centro Europeo de Formación Ambiental y Turística (CEFAT).

Drumm, A. y Moore, A. (2002). Desarrollo de ecoturismo. Un manual para profesionales. Arlington, Virginia, USA: Editorial Alex C. Walker Educational \& Charitable Foundation. The Nature Conservancy.

Epler, M. (2002): Ecotourism: principles, practices $\mathcal{E}$ policies for sustainability. París:

United Nations Enviroment Programme (UNEP).

García, Y. (2007). "Consideraciones metodológicas en torno a «lo rural»: La complejidad de su definición”, en José Antonio Pérez (coord.). Los intangibles en el desarrollo rural. Cáceres: Universidad de Extremadura, Servicio de Publicaciones.

García, Y. y Blanco, R. (2008). «Una aproximación a los nuevos procesos de movilidad en el espacio rural de Extremadura», en XXI Seminario Internacional AISO: Desarrollo bumano: trabajo y cohesión social (24 a 26 de septiembre de 2008, Santiago de Chile).

García, Y*; Blanco, R. y Pérez, J. A. (2009). «Valoración de formas de vida y de obtención de rentas en el medio rural de Extremadura», en Moreno, 
L.; Sánchez, M. M., y Simoes, O. (coords.). Cultura, inovaçao e território: O Agroalimentar e o Rural, Lisboa: Sociedade Portuguesa de Estudos Rurais. García, Y.; Blanco, R., y Sánchez-Oro, M. (2011). «Aproximación a un segmento de mercado en el turismo rural: el caso del "turismo paisano" en Extremadura», en XXIV European Congress for Rural Sociology (22 a 25 de agosto de 2011, Chania, Creta, Grecia).

Martínez, V. (2009). Multiculturalismo en las sociedades del ocio. Madrid: Ediasa, Ediciones Académicas.

Martínez, V. (2011). Turismo y ocio en las sociedades. Dinamismo, desarrollo turístico y riesgos. Madrid: Ediasa, Ediciones Académicas.

Mathieson, A. y Wall, G. (1982). Tourism, economic, physical and social impacts. Singapore: Longman.

Macintyre, G. (1993). Desarrollo turístico sostenible. Guía para planificadores locales. Madrid: OMT.

Mc Neely, J. A. et alii (1995). Directrices: ordenación de los parques nacionales y de otras zonas protegidas para el turismo. Organización Mundial del Turismo.

Pérez, J. A. (2007). Los intangibles en el desarrollo rural. Cáceres: Universidad de Extremadura, Servicio de Publicaciones.

Pérez, J. A. (2007). Sociología y desarrollo: el reto del desarrollo sostenible. Madrid: Ministerio de Agricultura, Pesca y Alimentación.

Pérez, J. A. y Sánchez-Oro, M. (2007). «Perspectivas y orientaciones ante el futuro del desarrollo rural», en Pérez, J. A. (coord.). Los intangibles en el desarrollo rural. Cáceres: Universidad de Extremadura, Servicio de Publicaciones.

OMT (2001). Código ético mundial para el turismo. Resolución adoptada por la Asamblea General de las Naciones Unidas, 21 de diciembre de 2001, A/ $\mathrm{RES} / 56 / 212$.

OMT (2011). Barómetro OMT del Turismo mundial, vol. 9, n.* 1, febrero.

Sánchez-Oro, M. y García, Y. (2010). «Empresarios turísticos (casas rurales) en áreas rurales alejadas del sur de Europa. Perspectivas y valoraciones del medio rural donde se instalan. El caso de las Villuercas y Sierra de Gata (Extremadura, España)», en Blanco, R. y Pérez, J. A. (coords.). Presente y futuro de la sociología de la empresa y de las organizaciones: contribuciones desde el ámbito docente e investigador. Zaragoza: Egido.

Yunis, E. (2004), «El imperativo de la sostenibilidad en el turismo del siglo xx». Forum Barcelona 2004. Intervención del jefe de desarrollo sostenible, OMT, julio, p. 9 . 